\title{
EL ESPAÑOL HABLADO EN CUBA: PRÉSTAMOS VIGENTES, LEXICOGÉNESIS Y VARIACIÓN LINGÜÍSTICA
}

\author{
Dalila Fasla Fernández \\ Universidad de La Rioja
}

\begin{abstract}
RESUMEN: La variedad de español hablada en Cuba, como parte integrante del español del Caribe, presenta en su nivel léxico un abundante caudal de préstamos de diverso origen etimológico (indigenismos, afronegrismos, anglicismos y galicismos, inter alia); en este trabajo ofrecemos un muestreo detallado de dichas voces, así como una clasificación de fenómenos que justifican su integración en el sistema receptor y que son prueba de su rendimiento morfológico y sociosemántico: v. gr., hibridación morfológica por derivación, lexicalización, cambio semántico y formación de dobletes semánticos por influencia de la variación diatópica o diafásica.
\end{abstract}

ABSTRACT: The variety of Spanish spoken in Cuba, which is a Caribbean Spanish dialect, features at the lexical level an abundance of loan words from various etymological origins (indigenisms, afroamericanisms, anglicisms, gallicisms, among others). In the present research we offer an exhaustive sampling of words of this kind and a taxonomy of the phenomena that motivate their integration into the system that has borrowed them. Among such phenomena, which are proof of the morphological and socio-semantic productiveness of these loan words, we have morphological hybridization through derivation, lexicalization, semantic change, and the formation of semantic doublets through the influence of diatopic and diaphasic variation.

PALABRAS CLAVE: Contacto de lenguas, aculturación, préstamo léxico, sinonimia, variación lingüística.

KEYWORDS: Language contact, acculturation, lexical borrowing, synonymy, linguistic variation.

* La autora pertenece al Centro de Investigación en Lenguas Aplicadas (CILAP) de la Universidad de La Rioja. 


\section{Descripción sociolingüística}

La variedad de español hablada en Cuba forma parte del complejo dialectal conocido como español antillano, integrado a su vez, por el dominicano y el puertorriqueño; este contexto sociogeográfico ${ }^{1}$ muestra que la historia colonial de la isla -marcada por procesos de aculturación, transculturación ${ }^{2}$ y deculturación de carácter discontinuo- atestigua un amplio panorama de lenguas en contacto directo, cuyas directrices más representativas esbozamos a continuación:

(a) En primer lugar, el sello de identidad propio de la variedad cubana tiene su origen en el contacto que se establece, a partir de 1510, entre la lengua arahuaca antillana y el español peninsular de los colonos, hecho reiteradamente señalado en un buen número de aportaciones clásicas, así como en contribuciones más recientes (cf., v. gr., Valdés Bernal 1999: 224; Choy López 1999: 82-85; Aleza y Enguita 2002: 23; Menéndez 2004: 101). Esta situación lingüística, ligada al inicio del mestizaje (biológico y cultural) como correlato exógeno, ha dado lugar a la adaptación de un número significativo de voces tomadas como préstamos para designar las nuevas realidades de ultramar; el común denominador de los referentes designados con estos aruaquismos guardan relación con el hábitat y con la cultura indoantillana, o bien con fenómenos naturales propios de este dominio geográfico. Lejos de ser un fenómeno aislado, el español de los colonizadores entra en contacto, a su vez, con otras lenguas amerindias como el caribe, el náhuatl, el quechua o el guaraní, entre otras, hecho que revela la extensión de la colonización hacia la zona continental -así como el desplazamiento de pueblos indoamericanos de regiones geográficas próximas a la isla- y que se refleja en la consecuente prestación léxica, fruto de la simbiosis étnico-cultural.

(b) No menos representativa resulta la llegada a la isla de fuerza esclava de origen subsahariano a partir de 1517. El golfo de Guinea y las regiones del Congo y Angola fueron las zonas que aportaron el mayor contingente de mano de obra; de este modo, la comunidad negra procedente de África dio lugar a una nueva situación de lenguas en contacto directo, que deriva en la prestación de un buen

1. El archipiélago objeto de nuestro estudio -que presenta la localización más occidental de Las Antillas Mayores- está constituido por la isla de Cuba (popularmente conocida como la perla del Caribe o de Las Antillas, cf. el origen de esta denominación en Barcia Zequeira, 2001-03: 25-27), la isla de la Juventud y más de un millar de isletas y cayos adyacentes que se agrupan, a su vez, en cuatro subarchipiélagos: Los Colorados, Jardines del Rey, Jardines de la Reina y Canarreos. En cuanto a su división político-administrativa, la República de Cuba se divide en 14 provincias y el municipio isla de la Juventud: (a) zona occidental.- Pinar del Río, La Habana (el núcleo más cosmopolita del país), Ciudad de La Habana, Matanzas y la isla de la Juventud; (b) zona central.- Cienfuegos, Villa Clara, Sancti Spíritus, Ciego de Ávila y Camagüey; (c) zona oriental.- Las Tunas, Holguín, Granma, Santiago de Cuba y Guantánamo. 
número de voces tomadas de las lenguas habladas por dicha comunidad negra, los afronegrismos. Llama especialmente la atención, en este sentido, que este constituyente étnico de la sociedad cubana -sometido al conocido proceso de transculturación afrohispánico y vital en la formación del correspondiente regiolectoestuvo marcado por una diversidad lingüística previamente planificada,

exacerbada por los propios dueños de ingenios, quienes intencionalmente constituían las dotaciones con esclavos de las más diversas procedencias, para que ninguna lengua subsaharana $[($ sic $)]$ sirviese de medio de comunicación y de reforzamiento identitario e ideológico (Valdés Bernal 2007: 42).

Así, debido a la variada procedencia etnolingüística de los pueblos implicados en este tipo de ocupación (principalmente mandingas, gangás, minas, lucumíes, carabalies y congos) ${ }^{3}$, los afronegrismos vigentes en la modalidad cubana presentan menor extensión diatópica que los indigenismos y pueden sistematizarse en diferentes categorías funcionales: en este sentido, debemos distinguir los afronegrismos que muestran un uso ampliamente extendido (sintópica y sinstráticamente), pues son los préstamos típicos de palabra y cosa, así como aquellos que están coloquialmente marcados $\mathrm{y}$, por último, los afronegrismos propios del estrato marginal.

(c) Mención aparte merece el contacto con el francés y con el inglés. Así, la inmigración antillana iniciada a finales del siglo XVIII, procedente de Haití (ca. 1791) y de Jamaica (ca. 1912), presenta un peso demográfico significativo. Sin embargo, los préstamos tomados del criollo francés hablado en Haití (créole) se documentan tan solo como casos aislados y muestran un uso preponderante en la zona oriental de la isla ${ }^{4}$. En el caso del inglés, la presencia del angloantillano -representado sobre todo por la figura del bracero jamaicano- adquiere un notable grado de influencia en las primeras décadas del siglo XX; por otra parte, sin olvidar el exi-

2. En cuanto a la caracterización de este fenómeno como la "recepción de modelos culturales externos", de acuerdo con la definición clásica, vid. Ortiz ([1940] 1978: 93 y 97) y sobre todo la excelente síntesis de Toro, quien relaciona los espacios transculturales con la teoría de la hibridación y señala que "el prefijo trans- $[\ldots]$ se entiende como un diálogo desjerarquizado, abierto y nómada que hace confluir diversas identidades y culturas en una interacción dinámica" (2006: 17; cf. 15 y 25).

3. En palabras de Ortiz, "mandingas, lucumíes, carabalíes y congos fueron los negros más abundantes en Cuba, pero ninguno de ellos en particular puede estimarse como predominante" (1922: 326). Cf. los comentarios críticos de López Morales sobre la identificación étnica de las comunidades negras llevadas a Cuba (1971: 31-32, texto y notas 37-38), así como las reflexiones recogidas en Valdés Bernal (1978: 98-99 y 1996-97); por otra parte, en función del mayor o menor dominio de la lengua española se han distinguido cuatro tipos de negros hispanohablantes: bozales, ladinos, criollos y curros (cf. Valdés Bernal 1998: 76-79).

4. Sobre esta variedad de español haitianizado, vid. el artículo de Ortiz López (1999: 430 y ss.) especialmente centrado en la morfosintaxis. 
guo caudal de inmigrantes anglófonos de diversa procedencia geográfica (norteamericanos, británicos, canadienses...) -y al margen de la conocida toma de La Habana por los ingleses en 1762- el contacto con el inglés alcanza especial relevancia ya en el siglo XX, en el periodo neocolonial (1902-1958) ${ }^{5}$, situación que, como es bien sabido, cambia drásticamente a partir del triunfo de la Revolución cubana en $1959^{6}$.

En último término, consignamos ciertos casos de contacto que no han derivado ulteriormente en la adopción de préstamos léxicos y que de nuevo constituyen un fenómeno consecuente al desplazamiento de determinados núcleos migratorios:

(d.1) En este sentido, las lenguas semíticas constituyen la fuente de contacto más influyente debido a la inmigración árabe atestiguada en la primera mitad del siglo XX, si bien el corpus de arabismos vigentes en el español hablado en Cuba fue transmitido durante el proceso de colonización; por otra parte, el contexto sociolingüístico en el que se produce la emigración de judíos hacia Cuba revela la convivencia de dos comunidades diferenciadas tanto en su procedencia geográfica como en su lengua: por un lado, los sefarditas (hablantes de judeoespañol) y, por otro, los asquenazíes (cuyo signo de identidad es el judeoalemán o yiddish), emigrados en su mayor parte a EE.UU ya en la década de los sesenta; igual que en los casos anteriores, los hebraísmos vigentes en la modalidad cubana no se deben al contacto lingüístico interétnico, sino que han sido heredados del español peninsular.

(d.2) En segundo lugar, destaca asimismo la inmigración de chinos y japoneses, iniciada a mediados del siglo $\mathrm{XIX}^{7}$, contacto que no ha producido préstamos léxicos por vía directa, dado que dichos préstamos llegan a Cuba a través del español peninsular. Transcurridas varias décadas, ya a principios del siglo XX se producen nuevos movimientos migratorios (coreanos e indostanos); sin embargo, las voces de origen indostano han sido heredadas también del español general, o bien se han introducido en nuestra lengua a través del francés o del inglés.

(d.3) Frente a estas fuentes de contacto, cabe señalar asimismo la inmigración procedente de focos geográficos europeos, como por ejemplo, Italia; no obstante, salvo ciertos casos aislados, los italianismos vigentes en el español hablado en Cuba son heredados del español general: ello se debe a que dicho núcleo de población

5. Etapa que también se conoce bajo la denominación de República mediatizada o Pseudo-República.

6. La nueva realidad sociolingüística derivada de este hecho histórico favoreció la desaparición progresiva de muchos anglicismos transmitidos sobre todo a través de los medios de comunicación.

7. Sobre la influencia del chino en el español hablado en Cuba, vid. Figueroa (2008), quien ofrece un estudio histórico basado en datos cuantitativos acerca de la inmigración china, así como una detallada caracterización lingüística de esta variedad de español en contacto. 
migratoria fue poco representativo "(en 1899 eran 114, y en 1931 representaban el 0,3\% del total de extranjeros radicados en Cuba)" (Valdés Bernal 1999: 232).

Así pues, el marco histórico que nos ocupa revela la colonización de la isla como un hecho paralelo a sucesivos fenómenos de contacto de lenguas, de diferente grado de influencia sociocultural, duración e intensidad; de este modo, la población cubana -formada en su mayor parte por descendientes de inmigrantes españoles- presenta un alto nivel de mestizaje ${ }^{8}$, fruto de la diversidad racial y con una convergencia parcial en su dimensión diacrónica. Puede comprobarse, por otra parte, que estas diferentes situaciones de contacto lingüístico y cultural -prolongadas en el tiempo y en el espacio geográfico- han dado lugar, en determinados casos, a un buen número de fenómenos constitutivos de una realidad sociolingüística compleja y heterogénea; en este sentido, destacan especialmente la interferencia y el préstamo léxico, derivados del contacto entre sistemas. Sin embargo, frente a estos indicadores primarios de contacto pueden identificarse asimismo otros fenómenos concomitantes de carácter externo (v. gr., aculturación, biculturación, deculturación, diglosia, hibridación lingüística y étnico-cultural ${ }^{9}$, integración-marginación, multilingüismo, transculturación $)^{10}$, favorecidos en cambio por el contacto intrasocial e intercultural sistemáticamente asociado a la convivencia interétnica.

De acuerdo con nuestro objeto de estudio, que se plantea como una contribución al uso de los préstamos léxicos en la norma general del español hablado en $\mathrm{Cuba}^{11}$, debemos recordar que el rendimiento morfosemántico asociado a los

8. Como ejemplo de etnias representativas de este fenómeno en todas sus acepciones, cabe citar la comunidad blanca, negra, india o china.

9. Cf. el artículo ya citado de Toro (2006: esp. 15-25) en el que se revisa exhaustivamente el marco teórico referente a la hibridez en todas sus acepciones, i. e., de acuerdo con el campo disciplinario correspondiente.

10. Algunas de estas consecuencias sociolingüísticas del contacto quedan atestiguadas a través de la figura del intérprete indio y español; sobre el papel de los intérpretes vid. Martinell (1992: 151-181), así como la bibliografía consignada en dichas páginas.

11. Los datos recogidos en el muestreo léxico consignado en los apartados que siguen han sido comprobados, contrastados y verificados a través de informantes de distintos grupos de edad, así como de diferente pertenencia diastrática y de diversa adscripción sintópica (occidental-central-oriental), durante sucesivas estancias en la isla, en los años 1998-2008. Los informantes seleccionados responden, a su vez, a perfiles diatópico-diastráticos de distinta índole (i. e., áreas urbanas vs. áreas rurales), hecho significativo si recordamos que en Cuba los datos sociodemográficos actuales indican que la población es mayoritariamente urbana (aproximadamente un 75\%); cf. los porcentajes de las últimas décadas en Ueda y Ruiz Tinoco (2003: 192 y 194). Como es evidente, esta información nos ha sido especialmente útil y relevante a la hora de interpretar o corregir ciertas ambigüedades, vaguedades e imprecisiones consignadas en ciertos repertorios lexicográficos carentes de rigor científico. Asimismo los ejemplos allegados en las diferentes partes que conforman este trabajo han sido cotejados en las siguientes fuentes: Ortiz (1985), Sánchez-Boudy (1999), Haensch, G. y Werner, R. (2000), Guerrero Ruiz et al. (2002). 
mecanismos de prestación léxica, forma parte de un fenómeno más amplio, configurado por un conjunto de etapas que, a modo de continuum, conforman el proceso de integración sociolingüística ${ }^{12}$ del préstamo en la lengua receptora:

- Interferencia léxica motivada por causas lingüísticas y extralingüísticas.

- Fase de prestación(-adaptación)-adopción.

- Productividad morfosemántica del préstamo (exploitation).

Al hilo de las puntualizaciones cronológicas allegadas debemos añadir además que los afronegrismos y los italianismos se adoptan sobre todo en el siglo XVI, algunos italianismos son más tardíos (ca. s. XIX), y entre estos ejemplos se encuentran voces que forman parte de la terminología musical moderna (adagio, andantino, concertino, moderato...), heredadas del español general; la adopción de galicismos predomina hacia finales del s. XVIII y se extiende hasta los años $30 \mathrm{y}$, por último, el caudal de anglicismos responde a la influencia sociocultural vigente hoy día.

El análisis sociohistórico de estas diferentes situaciones de contacto de lenguas identifica la diatopía cubana como una comunidad multicultural, conformada por puntos de intersección de dirección convergente, en la que conviven diferentes grupos sociales, costumbres, culturas, lenguas y etnias.

\section{Causas del préstamo léxico}

Al hilo de las revisiones teóricas más representativas sobre la motivación del préstamo léxico como fenómeno de sistema (cf. Gómez Capuz 1998: 255-272 y Hope 1971: 668-675 y 722-738) y teniendo en cuenta que la tipología de causas que pueden aducirse (sistemáticas o variables, externas o internas), se encuentra en función de las coordenadas sociolingüísticas asociadas a la situación de contacto de que se trate, detallamos a continuación los principales factores coadyuvantes que explican la adopción de voces tomadas de otras lenguas en la variedad de español hablado en la diatopía cubana (cf. Fasla 2008: 65-68):

(a) La necesidad de designar nuevas realidades, fundamentada en la inadecuación léxica de la lengua de los colonizadores; constituye, por tanto, una causa

12. Proceso conformado, a su vez, por dos vertientes: la integración lingüística (adaptación morfonológica, morfosintáctica, morfoléxica a la LR) y la integración social (frecuencia de uso, uniformidad de uso de las variantes, grado de aceptabilidad, actitudes) (cf. Clyne 1972: 14-19). 
universal subyacente a todo fenómeno de prestación que registre vacíos léxicos en la lengua receptora.

(b) La influencia del sustrato indígena arahuaco.

(c) El adstrato afroindígena, determinado por el proceso de transculturación y deculturación de las comunidades negras, así como por la asimilación de elementos culturales procedentes de grupos amerindios no cubanos.

(d) La influencia de adstrato debida al contacto con el inglés y el francés, aunque en el primer caso, hoy día se mantiene tan solo su influencia como adstrato cultural; no obstante, muchas de las voces tomadas de esta lengua son en realidad auténticos extranjerismos (v. gr., cake, bridge, marketing, show, smoking, switch, ticket).

(e) La voz prestada hace innecesario el uso de la construcción perifrástica, contribuyendo su adopción y ulterior adaptación morfonológica a la economía lingüística: v. gr., alcatraz 'pelicano marino', bohío 'vivienda rústica', butaca 'asiento rústico', cayo 'isla rasa', closet 'armario empotrado', congrí 'moros y cristianos, arroz con fréjoles', creyón 'barra de labios', curiel 'conejillo de Indias', fongo 'plátano burro', manatí 'vaca marina'.

(f) La necesidad de comunicación con los diferentes grupos étnicos en contacto, originada en la consecuente hibridación lingüística y sociocultural.

(g) El uso del préstamo como marcador de pertenencia grupal, sobre todo aquellos que hacen referencia a formas musicales, instrumentos y danzas, al sistema de valores y creencias o a la gastronomía, dado que remiten al componente cultural de la identidad como distintivo del grupo social.

De acuerdo con el marco etnolingüístico y sociogeográfico en el que se desarrollan las primeras fases de la colonización, debemos añadir además un factor que ejerció especial influencia en el proceso de adopción, transmisión y consolidación del tipo de préstamo conocido como indigenismo antillano: se trata del mestizaje asociado a la situación de contacto étnico ya referida y representado, en su etapa más primitiva, por los colonos españoles y los tres grupos culturales indocubanos (guanahatabeyes, siboneyes y tainos) $)^{13}$.

13. Denominaciones clásicas, hoy día generalmente sustituidas por los términos preagroalfarero, protoagrícola y agroalfarero (vid. Valdés Bernal 1984: 8, nota 1; 1999: 223 y Pichardo Moya 1956: 710); cf. asimismo las reflexiones críticas allegadas en el artículo de López Morales (1996-97). 
Al hilo de las observaciones que anteceden y dado el marco histórico al que remite nuestro objeto de estudio -brevemente bosquejado en las primeras páginas- exponemos a continuación un muestreo de préstamos heredados de la variedad peninsular (v. gr., arabismos, gitanismos, lusismos, italianismos, vid. infra, § 3 ), así como de préstamos favorecidos por el contacto directo entre la lengua fuente y la lengua receptora (i. e., indigenismos, afronegrismos, galicismos y anglicismos, vid. infra, 4).

\section{Préstamos heredados del regiolecto peninsular}

Las fuentes que versan sobre el origen de los pobladores del Nuevo Mundo coinciden en señalar que contribuyeron especialmente las regiones de Andalucía y del occidente peninsular (vid. Henríquez Ureña 1976: 55 y ss.; Martínez-Shaw 1998: passim ${ }^{14}$, de modo que durante el proceso de colonización, el porcentaje de emigrantes procedentes de estas regiones geográficas supera significativamente las cifras de colonos provenientes de otras regiones peninsulares; por otra parte, no debemos olvidar que el mediodía peninsular ha sido uno de los focos más directamente influidos por la invasión árabe, en el que Andalucía se identifica como heredera directa del legado de al-Andalus. Resulta significativo comprobar asimismo que en la época en que se produjeron los primeros asentamientos de colonos en el continente americano, la civilización del Islam hispano había llegado a su ocaso. De esto se sigue que, cuando los andaluces poblaron las nuevas tierras, llevaban en su dialecto un considerable número de $\operatorname{arabismos}^{15}$, cuya vitalidad y vigencia puede documentarse hoy día en el español ultramarino ${ }^{16}$.

(a) En el caso concreto de la variedad diatópica cubana, es bien sabido que España participó activamente en el poblamiento de la isla con un predominio significativo de inmigrantes de la zona meridional: así, hasta la primera mitad del siglo XVII es considerable el porcentaje de andaluces emigrados y a partir de la

14. Como es bien sabido la teoría andalucista ha sido ampliamente debatida y cuenta hoy día con una representativa nómina de seguidores y detractores (vid. Fasla y Concepción 2000: 105, texto y nota 3).

15. Frente al exiguo número de voces de origen mozárabe (amapola) o bereber (alfaneque, ant.), cuya prestación data del mismo periodo histórico.

16. La vigencia de los arabismos adoptados en la variedad patrimonial, cuya prestación tiene lugar en el contexto de la España islámica medieval, puede obedecer en ciertos casos a la influencia de la variación lingüística (cf. Fasla 1999-2000), fenómeno que puede comprobarse asimismo en la variedad americana; en cuanto al proceso de arcaización de ciertas voces de origen árabe en ambas variedades, vid. Fasla y Concepción (2000: 114-115). 
segunda mitad del siglo, resulta significativo el porcentaje de canarios; este hecho condicionó la variante cubana en todos los niveles del sistema, "haciéndola más parecida a las variantes andaluza y canaria" (cf. Valdés Bernal 1999: 231), y particularmente en el nivel léxico, que atesora hoy día un abundante caudal de voces de origen árabe (v. gr., aceite, aceituna, acemita, albahaca, alcuza, alfajor, alfiler, algarroba, algodón, aljibe, almacén, almadía, almíbar, almohada, arroz, azúcar, azucena, azul, candil, maroma, naranja, tarea, toronja, zapato, zocato), algunas de ellas en proceso de arcaización (v. gr., alcayata, aldaba, anafe) ${ }^{17}$. No obstante, el uso de arabismos no cubría las necesidades de designación del habitat ultramarino, hecho que motivó la adopción de voces tomadas del arahuaco insular; en palabras de Valdés:

algunos ejemplos [del uso] de voces árabes a objetos americanos aparecen en el Diario de navegación y [en] las Cartas de Cristóbal Colón [... pero] ni aún recurriendo al árabe lograron satisfacer las necesidades que exigía la comunicación en el nuevo entorno americano. Por este motivo, se vieron obligados a apelar al léxico de la primera lengua indoamericana con que entraron en contacto (1984: 12).

(b) Un segundo grupo de préstamos heredados del español peninsular está constituido por voces de origen gitano, que se integran en la variedad cubana sobre todo a través de la modalidad andaluza y canaria, aunque hoy día dichas voces muestran una amplia dispersión diatópica peninsular; estos gitanismos son absolutamente frecuentes en el habla popular cubana: v. gr., belén, chalao, chaval, jarana, jeta, menda, postín, prajo, puró, sandunga ${ }^{18}$.

(c) En un último apartado consignamos préstamos de otras lenguas, cuya valoración cuantitativa muestra un menor grado de influencia de los grupos étnicos implicados en el mecanismo de prestación; así, cabe citar entre otros préstamos, lusismos $^{19}$ (v. gr., botar, cachalote, cachimba, chamuscar, frijol, marejada, mojo, virar), italianismos ${ }^{20}$ (v. gr., arlequín, contralto, dúo, espagueti), japone-

17. La mayor parte de los arabismos heredados conserva el significado conocido en la variedad peninsular, si bien pueden encontrarse excepciones a esta tendencia: v. gr., aldaba 'tabaco, moneda', alfarda 'viga', almanaque 'año (edad)'.

18. Vid. la relación que se recoge en Valdés Bernal (1990: 213-221).

19. Como ha señalado Granda, la emigración a América de andaluces occidentales y de canarios (primera y segunda vías indirectas), constituye una importante fuente de transmisión de la mayor parte de los lusismos vigentes en el español hablado en Cuba; en cuanto a la tercera vía indirecta, ésta se debe a la emigración de colonos procedentes de la franja occidental peninsular, limítrofe con Portugal (cf. Granda 1968: 14 y Valdés Bernal 1994b: 68-69).

20. Salvo ciertos casos aislados, la mayor parte de los italianismos vigentes en el español hablado en Cuba constituyen préstamos heredados. 
sismos (v. gr., biombo, catana, judo, kimono, samurai, soya, sunami), cantonesismos (v. gr., caolín, charol, té), hebraísmos (v. gr., aleluya, querubín), e indostanismos (v. gr., avatar, bambú, lancha), todos ellos heredados del regiolecto peninsular y transmitidos en el proceso de colonización.

\section{Préstamos motivados por el contacto lingüístico y sociocultural}

Las diferentes fases de poblamiento de la isla dieron lugar, desde la época del periodo antillano (1493-1519), a complejos mecanismos de interferencia lingüística entre la lengua de sustrato (arahuaco insular), hablada por la población indígena autóctona, y la lengua del grupo étnico invasor; por otra parte, el asentamiento de colonos en sucesivas fases migratorias, estuvo ligado al empleo del pueblo aborigen como fuerza de trabajo esclava con el fin de poder explotar las riquezas naturales propias del nuevo habitat. De este modo, surgió una amplia tipología de relaciones administrativas y socio-económicas entre ambos grupos, hecho que -unido a la necesidad de designar referentes absolutamente desconocidos en el suelo peninsular ${ }^{21}$ - derivó inevitablemente en la adopción de un significativo número de voces tomadas de la lengua hablada por los indios cubanos, en su papel de sociedad dominada. A pesar de la falta de afinidad genética entre la lengua fuente y la lengua receptora, el mecanismo de prestación se vió favorecido por la estructura lingüística de la lengua arahuaca, de perfil silábico muy similar al del español y con un elevado grado de correspondencia en el vocalismo y en el consonantismo; además,

el hecho de que los españoles no emprendieron la conquista de las tierras americanas
continentales hasta un cuarto de siglo después de descubiertas y colonizadas las Anti-
llas Mayores, favoreció en grado sumo la unificación de las denominaciones, puesto
que los vocablos indios utilizados por los primeros pobladores europeos se transmitie-
ron a los posteriores, con lo que se fijaba su uso en la lengua (Valdés Bernal 1988: 405).

Todos estos factores han contribuido, en buena medida, a que los indigenismos arahuacos constituyan un grupo predominante respecto de los préstamos tomados de otras lenguas amerindias. Con posterioridad a esta primera fase de prestación, la lengua de los colonos entra en contacto con otras lenguas indígenas, debido básicamente a dos factores: por una parte, la extensión de la colonización hacia el continente y la centralización del puerto de La Habana como punto de

21. Excepción hecha de la toponimia (Camagüey, Cuba, Guamá, Guanabacoa, Guanahacibibes, Habana, Zaza...), los préstamos más abundantes son términos designativos de la flora y la fauna. 
encuentro para entrar o salir de la isla y, por otra, la importación de mano de obra esclava no indocubana, procedente de otras áreas geográficas: v. gr., los caribes insulares, asentados en Las Antillas Menores, los caribes continentales (procedentes en algunos casos de las costas de Venezuela o de la isla de Margarita) ${ }^{22}$, o bien, los indios de origen mexicano, de introducción más tardía (ca. ss. XVIII-XIX).

(a) De acuerdo con estos postulados teóricos, ofrecemos a continuación un muestreo clasificatorio de indoamericanismos hoy día vigentes en el español hablado en Cuba; bajo este término genérico englobamos, en primer lugar, los aruaquismos, que como ya hemos señalado caracterizan especialmente la variedad diatópica cubana y, en siguiente lugar allegamos ciertos indigenismos tomados de otras lenguas amerindias, que han contribuido igualmente a la formación del regiolecto cubano: entre las más representativas, el caribe (insular y continental o cumanagoto), el nahua y el quechua ${ }^{23}$ :

\section{(a.1) Indigenismos antillanos ${ }^{24}$ :}

A. Del taíno (arahuaco ${ }^{25}$ insular) $^{26}$ : v. gr., ají, areíto, barbacoa, batata, bohío, caimán, canoa, caoba, carey, cayo, cazabe, chipojo, conuco, curiel, enaguas, guacamayo, guanábana, guaraguao, guayaba, guayacán, güiro, hamaca,

22. No se nos oculta que, debido a la situación de contacto directo entre taínos y caribes, muchos de los caribismos vigentes en el español hablado en Las Antillas, son en realidad voces prestadas del caribe insular o continental y adaptadas al arahuaco como lengua receptora, hecho que se refleja con frecuencia en la confusión etimológica consignada en los diccionarios de la lengua.

23. Resulta muy exiguo el porcentaje de voces de origen tupí-guaraní (v. gr., ananás 'piña', maracas 'instrumento marcador del ritmo en los conjuntos populares de carácter vocal e instrumental', petunia 'planta solanácea') o maya (v. gr., henequén 'pita').

24. Quedan excluidos del muestreo supuestos indigenismos (v. gr., boniato, jimagua, tabaco) reiteradamente aducidos como tales en recopilaciones de indoamericanismos de orientación metodológica muy diversa (cf. López Morales 1971: 52 y DCECH: s. vv.); el origen del término jimagua remite a "dos santos idénticos de las religiones africanas" (Sanchéz-Boudy 1999: s. v.).

25. Hemos adoptado la variante más moderna del término, si bien las variantes fónicas aruaco, arauaco (o Arawak, Aruak) se documentan asimismo con relativa frecuencia.

26. Existe una cierta confusión de conceptos entre ambos términos (taíno y arahuaco), debido a un fenómeno de extensión semántica, pues como señala Buesa Oliver, "el arahuaco insular de Haití, Santo Domingo, Puerto Rico, Cuba, Jamaica y de otras islas antillanas se ha llamado comúnmente taíno; al principio era el nombre de la tribu arahuaca encontrada por los españoles en Haití, para pasar después a designar a [sic] la lengua hablada por dicha tribu" (1965: 21). En cuanto al significado del préstamo, se trata de una formación por flexión en la que el sufijo de plural masculino -no se anexiona a la base taí 'noble, prudente'; así, taíno significa literalmente 'nobles, prudentes', i. e., 'no caníbales' (cf. Arrom 1989: 53) y la forma taínos constituye, por tanto, una reduplicación de la marca de número (plural híbrido).

Vid. asimismo las precisiones terminológicas que se detallan en el artículo de Valdés Bernal dedicado al estudio del arahuaco insular, trabajo en el que además se recoge una extensa relación de aruaquismos (más de 300 voces) (1984: nota 1 y 17-18). 
huracán, iguana, jíbaro, jicotea, jutía, liana, maguey, maíz, majagua, mamey, mangle, maní, seboruco, serensé, tiburón, yuca.

B. Del caribe: v. gr., arepa, bejuco, butaca, cabuya, cacique, caguama, caguará, caníbal, colibrí, daiquirí, guacharaca, guasón, loro, manatí, mangle, mico, papaya, piragua, sabana, turpial.

(a.2) Nahuatlismos: v. gr., aguacate, cacao, chapapote, chicle, chile, chocolate, chuchumeca, guacal, guacamole, hule, jicara, papalote, petaca, petate, pinol, sinsonte, taco, tamal, tiza, tomate, zapote.

(a.3) Quechuismos: v. gr., carpa, chirimoya, guacarnaco, guano, papa.

Este caudal terminológico constituye, con notable frecuencia, la base léxica de nuevas formaciones basadas en los recursos morfosemánticos de la lengua receptora (vid. infra, 5). Como fuente productiva de procesos de lexicogénesis, la documentación histórica y actual vigencia de dichos términos atestigua, a su vez, la convivencia entre colonizadores y grupos indígenas de diversa procedencia geográfica, marcada por procesos discontinuos de aculturación; asimismo, permite comprobar "el reflejo en la lengua del proceso de formación del pueblo cubano [...], de los vínculos históricos y socioeconómicos que existieron entre Cuba y otras tierras de nuestra América en el pasado" (Valdés Bernal 1988: 415).

(b) La diversa procedencia étnica de las comunidades negras llegadas a Cuba dificultó considerablemente el proceso de prestación, que no partía en consecuencia de una única lengua fuente; en este sentido, compartimos la observación de Frago Gracia cuando afirma que "los africanos llegados a América hablaban multitud de lenguas, de modo que nunca constituyeron un sustrato, una fuerza lingüística mínimamente uniforme, lo cual sin duda limitó mucho su posibilidad de interferir en la lengua dominante" (1999: 295, el subrayado es nuestro).

Así, frente a los afronegrismos típicos del registro coloquial (v. gr., asere, bachata, butuba, cheche, cundango, ecobio, féferes, monina, ocambo, ;subuso!), muestran asimismo especial frecuencia de uso aquellos que forman parte de la terminología gastronómica o que hacen referencia a manifestaciones musicales, hoy día plenamente asimiladas e integradas en la sociedad cubana, sin olvidar el acervo de préstamos designativos de la flora y la fauna subsahariana o de realidades cotidianas propias de la cultura afrocubana (v. gr., banana, bemba, bembé, cumbé, cachimbo, conga, champola, chekeré, chimpancé, dengue, fufú, funche, guarapo, guineo, jimagua, jubo, macuto, majá, malanga, mambo, marimba, ñame, quimbombó, rumba, sambumbia, sirimba, tonga). Otros afronegrismos 
presentan, sin embargo, menor índice de frecuencia (v. gr., bongó, burundanga, mandinga), sobre todo en la generación más joven, por lo que pertenecen a la competencia pasiva de dicho grupo de hablantes; como señala López Morales, "la tercera generación es la que ofrece mayor índice de conservación de afronegrismos, seguida de la segunda; es decir, que a medida que bajamos en el espectro generacional aumenta la mortandad" (López Morales 1992: 265).

Como es obvio, a la luz de trabajos clásicos muy bien documentados (cf. Valdés Bernal 1978: 92-101, Alba 1992, López Morales 1992: 254-267), el análisis cuantitativo y cualitativo refleja que el caudal de afronegrismos es notablemente inferior al de indigenismos en el regiolecto antillano ${ }^{27}$; por otra parte, la relativa vitalidad de ciertos afronegrismos muestra proporcionalmente una tendencia al desuso léxico muy superior a la de los indoamericanismos.

(c) Préstamos de lenguas indoeuropeas:

La motivación de este grupo de préstamos se encuentra sobre todo en el contacto histórico atestiguado en la época colonial o en la influencia sociocultural vigente, en el caso del inglés, en la sincronía actual:

(c.1) Al margen del fenómeno de contacto asociado a la inmigración antillana (vid. supra, 1), del que data la adopción de voces tomadas del criollo francés (congrí, afió), es preciso subrayar el proceso de afrancesamiento imperante en la sociedad cubana del siglo XIX, que se extiende aproximadamente hasta el primer tercio del siglo XX, periodo en el cual la Luisiana francesa mantenía además una estrecha influencia en la zona occidental de la isla. En las dos últimas décadas de este periodo, el prestigio de la lengua francesa influye especialmente en el sociolecto representado por la burguesía criolla que, asentada sobre todo en la zona oriental de la isla, defendía a ultranza los ideales de la educación francesa, ideales que también hicieron eco en la España de los años 20.

Así, frente al vasto corpus de galicismos heredados del español peninsular (cf. Varela Merino 2009: esp. cap. I; 405 y ss.), resultan significativos en cambio aquellos que se adoptan bajo la influencia cultural francesa ya señalada; sin olvidar los galicismos de uso general en la cultura hispánica (v. gr., bufet, carrusel, champán, chimenea, compota, corchea, crema, cuplé, fular, garaje, hotel, taburete, taxímetro, tul), son típicos del español hablado en Cuba, v. gr., afer, afiche,

27. En este sentido, resulta significativo constatar que sólo seis afronegrismos constituyen la norma panantillana (cf. Alba 1992: cuadro 8). 
balance, bureo, carota, creyón, crupié, chalana, chambra, cheslón, chofer, garete, matiné, pantuflas, rendivú, surmenaje, tolete, trusó.

Esta doble vía de penetración constituye una importante fuente de variación fonética; de hecho, llaman especialmente la atención los galicismos que presentan diferente adaptación morfonológica en la diatopía cubana respecto de la solución peninsular: v. gr., bufet-buffet-bufé, chofer-chófer, cheslón-cheislón-chaiselongue, crupié-crupier.

(c.2) A través de la historia de Cuba, es posible constatar la presencia de comunidades antillanas anglohablantes, fundamentada en la importación de mano de obra, hecho que alcanza su mayor auge en las primeras décadas del siglo XX. Al hilo de este fenómeno de contacto, que corre paralelo a la vitalidad de otras variedades del inglés en diferentes enclaves del archipiélago cubano, conviene señalar que los anglicismos presentan hoy día un elevado índice de frecuencia en el sociolecto alto, a excepción de los términos designativos de referentes o acciones cotidianas como blume, budin, chanse, clinch, cloche, closet, doily, elevador, estray, guajiro, jon, panqué, parquear, ponchar, queque, soya, yoyó..., de uso general en todos los estratos y registros, así como en áreas urbanas y rurales.

Estos anglicismos locales y regionales conviven, no obstante, con anglicismos -ampliamente extendidos, al otro lado del Atlántico, por influencia socioculturalque muestran ocasionalmente variación fonética respecto de la variante peninsular (v. gr., beicon, bisté, champú, fútbol, estrés, mitin, poliéster, rosbif, suéter, zapin), así como con la incorporación, en las últimas décadas, de otros anglicismos de uso general que forman parte del léxico especializado sobre todo en el ámbito deportivo y en las nuevas tecnologías (v. gr., béisbol, cátcher, computadora, escáner, fotosop, internet, jonrón). Conviene señalar además que algunos de estos anglicismos, al igual que sucede en la variedad peninsular, pueden presentar una función eufemística (v. gr., liftin, overbukin, pilin, pircin); por otra parte, aunque en el ámbito hispanohablante estas voces se utilizan también como extranjerismos por influencia de la variación lingüística, su uso en la diatopía cubana muestra una mayor preferencia por la forma más evolucionada respecto del correspondiente término tomado de la lengua fuente (cf. lifting, overbooking, peeling, piercing) ${ }^{28}$.

En cuanto a la influencia de otros factores de variación lingüística como la edad y el sexo, en el primer caso es posible advertir una cierta tendencia al uso

28. Cf. el listado de anglicismos recopilado por Cárdenas Molina (1999), así como las observaciones recogidas en la monografía de Paz Pérez (1988: esp. 24-28). 
frecuente de anglicismos en la generación más joven; por otra parte, el generolecto masculino presenta asimismo una preferencia notable por el uso de este tipo de préstamos (cf. Domínguez Hernández 2006: 183).

A la luz de este muestreo de préstamos, bien sean heredados o bien motivados por el contacto directo, es posible identificar, a su vez, algunos marinerismos o voces naúticas (v. gr., aljibe, botar, chalana, garete, maroma, tolete, virar), que han desarrollado nuevas acepciones o sentidos durante el proceso de colonización para designar realidades no marítimas, manteniendo en ciertos casos su valor connotativo primitivo; como señala Cárdenas Molina, "a diferencia de lo que sucede en el español panhispánico, en el que gran parte de las voces marinas han perdido las connotaciones originarias, en el español cubano la inmensa mayoría de las voces recopiladas conservan muy viva su connotación marinera" (2002: 64).

Por lo que se refiere a la extensión diatópica del corpus de voces prestadas, condicionada en buena medida por la diferente influencia de la respectiva lengua fuente, así como por el variado grado de contacto sociocultural implicado en la adopción léxica, conviene señalar además que muchos de los préstamos vigentes en el español hablado en Cuba (sobre todo en el caso de los indigenismos), pueden tener no solamente un uso local, sino también regional (occid.-or.), panamericano o general. Así, por ejemplo, el uso de determinados préstamos está especialmente extendido en la zona dialectal circuncaribe (Santo Domingo, Puerto Rico, costas de Venezuela y parte de Colombia), debido no sólo al origen común de los pobladores precolombinos de Las Antillas Mayores (grupo etnolingüístico arahuaco), sino también a la extensión de la colonización hacia la zona continental; por último, forman parte del caudal del español general aquellos préstamos que han extendido su uso a la variedad peninsular (v. gr., aguacate, barbacoa, butaca, cacao, carpa, chicle, chirimoya, chocolate, hamaca, hule, loro, maíz, maní, petunia, piragua, tiburón, tiza, tomate), fenómeno favorecido por el flujo migratorio entre las dos orillas.

\section{Lexicogénesis, dobletes semánticos y variación lingüística (exploitation)}

La productividad morfosemántica del préstamo puede constatarse a través de una serie de fenómenos que se verifican en el proceso de adaptación morfoléxica de la voz tomada de la lengua fuente; así, muchas de las voces adoptadas se convierten en el eje de la derivación léxica, dando lugar a diferentes esquemas de hibridación, que se constituyen a expensas de afijos romances:

(a) En este sentido, la hibridación morfológica por derivación interviene en la formación de un buen número de nuevos términos y resulta especialmente producti- 
va en el caso de la sufijación (v. gr., aceitar, aguacatada, aguacatal, aguacatazo, barriotero, bejucal, bembita, bembón, bembetear, bembeteo, bongosero, cacagual, cacaotero, caguarita, chansesito, cundanguería, cutarazo, chirimoyal, guacalada, guajirada, guanajada, guarapería, guarapeta, guaraposo, guayabal, guayacol, hamaquear, hamaquero, huracanado, maicera, maizal, majagual, majagüero, malangal, mameyal, mameyazo, manglar, manglero, sabanero, sabanilla, seborucal).

(b) No obstante, la hibridación sobrepasa el ámbito de la palabra y se extiende asimismo al dominio sintagmático, debido a la integración del préstamo en locuciones o expresiones idiomáticas: v. gr., armar una guantanamera 'dar un escándalo', bailar la rumba 'dar coba'; disfrutar del mamey 'tener vacaciones'; estar de yuca y ñame 'en una situación difícil'; estar en el pico de la piragua 'correr un riesgo'; hacer un papalote 'perjudicar a alguien'; meterle al guarapo 'beber aguardiente'; ser de yuca y ñame 'de armas tomar'; ser una curiela 'tener facilidad para quedarse embarazada'; tener almanaquitis aguda 'estar muy viejo'; tener una indigestión de almanaque 'tener muchos años'; tocar la marimba 'fumar marihuana'; zumbar la berenjena '¡chúpate eso!'.

(c) Es frecuente observar un proceso de lexicalización ${ }^{29}$ en determinados términos híbridos fenómeno que, en ciertos casos, forma parte de un cambio semántico; de nuevo aquí son especialmente productivos los derivados (v. gr., aceitar, aceitoso, butacón, guaricandilla, guayabera, guayabero, guayabita (del Pinar), guayabito, guayabudo, hamaquero, jinetera, malanguita, papalotero ${ }^{30}$; con menor frecuencia pueden identificarse algunos compuestos (v. gr., aguaitacaimán, espantacaimán, pantimedias, pejenigua), y ciertos parasintéticos ${ }^{31}$ (v. gr., aguajirado, desmameyar).

Al margen de esta tipología de fenómenos indicadores de la madurez del préstamo, basados en la hibridación morfoléxica y sintagmática, puede identificarse asimismo un segundo grupo de fenómenos de carácter sociosemántico: la formación de dobletes semánticos a expensas del correspondiente sinónimo romance (o incluso entre préstamos), dobletes que deben su vitalidad y vigencia a la influencia de la variación lingüística:

29. A excepción de algún caso aislado de préstamo polisémico lexicalizado en todas sus acepciones (v. gr., guayabito) o de lexicalización de una acepción determinada, se trata generalmente de términos monosémicos.

30. Frente a la variante -ito, actualmente generalizada en la diatopía cubana, el sufijo -illo, de uso preponderante en la región occidental, se encuentra hoy día en retroceso, mientras que -ico presenta mayor frecuencia de uso en la zona oriental de la isla.

31. Son escasos los parasintéticos no lexicalizados, entre ellos destacan las formaciones analógicas para la designación del color: v. gr., achocolatado 'del color del chocolate', encabuyado 'atado con soga'. 
(d) En este sentido, la diversidad diatópica marca diferencias léxicas entre geosinónimos de uso preponderante en la zona occidental (central) u oriental de la isla ${ }^{32}$ (v. gr., arriero-guacaica, or.; camaleón-chipojo, or.; chancleta-cutara, or.; fruta bomba-papaya, or.; guajiro-campesino, or.; halcón-guaraguao, or.; harina de maíz-pinol, or.; harina (de maíz) cocida-serensé, or.; jimagua-mellizo, or.; marpacífico-amapola, or.; moros y cristianos-congrí, or.; niño-chichiguaco, or.; paseo-bureo, or.; platanito-guineo, or.; plátano burro-fongo, or.; soga-cabuya, or.).

No resulta difícil inferir que, de modo general, la voz prestada presenta una distribución sintópica en la zona oriental de la isla, mientras que el correspondiente sinónimo utilizado en la zona occidental es una formación romance; si bien, no se trata de un fenómeno sistemático, dado que se verifican asimismo casos de geosinónimos entre los propios préstamos (v. gr., henequén-maguey, or.; jicara-guacal, or.; mamey-zapote, or.; zanahoria-carota, or.) o entre voces patrimoniales (marpacifico-borrachona, or.).

(e) La variación diafásica, por otra parte, constituye asimismo un factor de vigencia y vitalidad del préstamo; así, la influencia de dicho factor contribuye a la formación de dobletes en los que uno de los dos miembros -generalmente el préstamo- constituye la forma culta, mientras que el otro presenta un uso coloquial (v. gr., aceite-grasa, acemita-bollo, alcoba-cuarto, alcuzas-vinagreras, alfarda-viga, cameraman-camarógrafo, cayo-islote, enaguas-sayuela, sabana-llanura, sirimba-desvanecimiento, tonga-pila).

Sin embargo, el grado de coloquialidad asociado al uso de ciertos afronegrismos ha influido notablemente en la diatopía cubana, hecho que contribuye asimismo a la formación de dobletes cuyos miembros integrantes pertenecen al registro coloquial; en este caso, la elección de sinónimos en dicha modalidad sinfásica se muestra condicionada por el factor edad (vid. supra, 4b) (v. gr., bachata-gozadera, burundanga-revoltijo, cundango-afeminado, féferes-trastos, guarapeta-borrachera, ñame-torpe, ocambo-veterano); si bien, en estas formaciones puede verificarse también la implicación de otros tipos de préstamos con diferente origen etimológico (v. gr., aldaba-cigarro, alforja-guanábana, ú. m. en pl., brei-receso, clinch-apretadera, desmameyar-desbaratar, guayaba-trola) ${ }^{33}$.

32. Cf. el diccionario de Pichardo y Tapia ([1836] $\left.1976^{5}\right)$, primer testimonio lexicográfico que registra la variación geolectal interna de la modalidad cubana decimonónica, si bien las anotaciones diatópicas no son sistemáticas, dado que su objetivo fundamental reside en constatar los usos generales.

33. Otras veces, se forman series sinonímicas en las que los correspondientes términos patrimoniales contrastan con el valor connotativo asociado al uso de la voz prestada: v. gr., cheche-oso-pendenciero, coloq. desp.; guayabito-amarillo-gallina, coloq. desp. 
De acuerdo con los ejemplos allegados como muestra representativa de esta tipología de fenómenos, es preciso señalar además que la vigencia y vitalidad del préstamo está en estrecha relación con su índice de productividad morfosemántica (v. gr., derivación, hibridación morfológica y sintagmática, lexicalización...), índice que responde, a su vez, a factores de carácter interno y externo: (a) entre los factores internos destaca el mayor o menor grado de creatividad léxica del sistema receptor, así como la capacidad connotativa y el uso metafórico de la voz prestada; y (b) como factores externos presenta una notable influencia la extensión diatópica y sociolectal del préstamo.

\section{Conclusiones}

El muestreo léxico consignado revela que el caudal de préstamos objeto de nuestro estudio presenta un notable grado de integración lingüística y social ${ }^{34}$; en términos cuantitativos, la mayor abundancia de indigenismos antillanos revela un mayor grado de contacto e influencia cultural del grupo taíno y caribe en la diatopía cubana: de hecho, no es casualidad que el mayor índice de productividad morfosemántica lo encontremos en este tipo de préstamos, que atestiguan un rendimiento morfológico y sociosemántico muy superior al aportado por el conjunto restante de voces prestadas. En cambio, la menor proporción de afronegrismos -cuya vitalidad de uso está marcada especialmente por el factor $e d a d$ y repercute en el enriquecimiento de la modalidad coloquial cubana- puede explicarse, en buena medida, por el proceso de deculturación impuesto a las comunidades negras; de hecho, como es bien sabido, los afronegrismos constituyen el componente lingüístico motivado por el proceso de transculturación afrohispánico en Las Antillas.

Al margen de dicha proporción cuantitativa, y a la luz de la revisión tipológica que precede puede comprobarse que un elevado porcentaje de los préstamos heredados, así como de los préstamos motivados por contacto lingüístico o sociocultural, se mantiene vigente hoy día en la vertiente hablada o escrita de la variedad cubana y muestran especial vitalidad en el uso coloquial, mientras que otros forman parte del léxico literario: v. gr., alfanje, areíto, caney, cemí, enagua, guainica, güije, nitaíno.

34. En este sentido, se verifican muy pocos casos de dobletes fónicos (v. gr., anafe-anafre; bloomer, bloome-blume; cacagual-cacahual; cemí-semí; chapapote-chapopote; chichiguaco-chichinguaco; guarapera-guarapería), cuya vacilación fonética no altera la uniformidad en el uso de las variantes. 
Resulta significativo señalar además que la distribución diatópica de los préstamos, y muy especialmente de los indigenismos, permite constatar diferentes grados de aculturación de acuerdo con el dominio geolectal; en este sentido, el asentamiento de los taínos en el extremo oriental del archipiélago, como grupo cultural indocubano más influyente, favoreció notablemente la diferenciación léxica debida a mecanismos de prestación, de modo que los aruaquismos presentan en esta sintopía un uso preponderante respecto del sinónimo patrimonial, ampliamente extendido en la modalidad occidental. Asimismo, dada la situación geográfica de dicha zona oriental, se constata la mayor vitalidad de otro tipo de préstamos, hecho que muestra la yuxtaposición de diferentes patrones culturales en contacto y que se manifiesta, en suma, en el correspondiente regiolecto. Así, la evolución histórica de las diferentes situaciones de contacto de lenguas, ligada a la propia dinámica de los movimientos migratorios en las direcciones señaladas, así como al origen geográfico de los colonos, constituye un factor contributivo en la gestación de la nación cubana como comunidad multicultural, cuya realidad sintópica regiolectal está determinada principalmente por fenómenos de sustrato y adstrato, acentuados, a su vez, por diferentes paradigmas de mestizaje.

\section{Bibliografía}

ALBA, O. "El español del Caribe: unidad frente a diversidad dialectal", Revista de Filología Española, 1992, 72/ 3-4, 525-539.

ALEZA IZQUIERDO, M. y J. Mª ENGUITA UTRILLA. El español de América: aproximación sincrónica. Valencia: Tirant lo Blanch, 2002.

ARROM, J. J. "La lengua de los taínos: aportes lingüísticos al conocimiento de su cosmovisión", en: La cultura taína, Actas del I Seminario sobre la situación de la investigación de la cultura taína. Madrid: Turner, 1989, 53-64.

BARCIA ZEQUEIRA, $\mathrm{M}^{\mathrm{a}}$ del C. "Sociedad imaginada: la isla de Cuba en el siglo XIX", Contrastes. Revista de historia moderna, 2001-2003, 12, 21-42.

BUESA OLIVER, T. Indoamericanismos léxicos en español. Madrid: CSIC, 1965.

BUESA OLIVER, T. y J. M ${ }^{a}$ ENGUITA UTRILLA. Léxico del español de América: su elemento patrimonial e indígena. Madrid: Mapfre, 1992.

CÁRDENAS MOLINA, G. "Voces marineras en el español de Cuba", en: ALEZA, M. (coord.): Estudios lingüísticos cubanos II. Universitat de València, 2002, 49-66.

CÁRDENAS MOLINA, G. "Arcaísmos léxicos en el español de Cuba", en: ALEZA, M. y J. SANMARTÍN (eds.). Estudios de lexicografía y léxico cubanos. Universitat de València, 2004, pp. 35-84. 
CÁRDENAS MOLINA, G. (2006): "Anglicismos en la norma léxica cubana”, en: ALEZA, M. et al. (eds.). El contacto lingüístico en el desarrollo de las lenguas occidentales. Quaderns de Filologia. Estudis Lingüístics, 2006, 4, pp. 15-57.

CASSÁ, R. Los indios de Las Antillas. Madrid: Mapfre, 1992.

CHOY LÓPEZ, L.R. Periodización y orígenes en la historia del español de Cuba. Valencia: Universitat de València, 1999.

CLYNE, M. Perspectives on Language Contact. Melbourne: Hawthorn Press, 1972.

COROMINAS, J. y J. A. PASCUAL. Diccionario crítico etimológico castellano e hispánico, 6 vols., Madrid: Gredos, 1991.

DE GRANDA, G. "Acerca de los portuguesismos en el español de América", Thesaurus, 1968, 23/ 2, 344-357.

DE TORO, A. "Figuras de la hibridez. Fernando Ortiz: transculturación. Roberto Fernández Retamar: Calibán", en: REGAZZONI, S. (ed.): Alma cubana: transculturación, mestizaje e hibridismo. Madrid/Frankfurt: Iberoamericana/Vervuert, 2006, 15-35.

DOMÍNGUEZ HERNÁNDEZ, M. “¿Comunión o transgresión? Nuevas reflexiones en torno al léxico culto de la ciudad de La Habana", en: KNAUER, G. et al. (eds.): Transgresiones cubanas. Cultura, literatura y lengua dentro y fuera de la isla. Madrid/ Frankfurt: Iberoamericana/ Vervuert, 2006, 175-190.

FASLA, D. "La adopción de arabismos como fuente de creación sinonímica en español (datos para un estudio sociosemántico)", Anuario de Lingüística Hispánica, 1999-2000, 15/ 16, 83-100.

FASLA, D. "Contribución al estudio de los arabismos en francés magrebí: identidad versus modernidad", en: Sociolinguistic Studies, 2008, 2.1: 61-95 [Disponible en: http://www.equinoxjournals.com/index.php/SS].

FASLA, D. y A. CONCEPCIÓN. "El léxico de origen árabe en el español de las dos orillas: anotaciones diacrónicas, diatópicas y sociolectales", Anuario de Estudios Filológicos, 2000, 23, 103-122.

FIGUEROA ARENCIBIA, J. "Aproximación al estudio del español chino hablado en Cuba", en: RILI, 2008, 6, no 1 (11), pp. 185-204.

FRAGO GRACIA, J.A. Historia del español de América. Madrid: Gredos, 1999.

FRAGO GRACIA, J.A. y M. FRANCO FIGUEROA. El español de América. Universidad de Cádiz, $2003^{2}$.

GARCÍA RIVERÓN, R. "El Atlas lingüístico de Cuba", en: Lingüística española actual, 1991, 13/ 2, 199-222.

GARRIDO DOMÍNGUEZ, A. Los orígenes del español de América, Madrid: Mapfre, 1992.

GÓMEZ CAPUZ, J. El préstamo lingüístico. Conceptos, problemas y métodos, Cuadernos de Filología, Anejo XXIX, Universitat de València, 1998. 
EL ESPAÑOL HABLADO EN CUBA: PRÉSTAMOS VIGENTES, LEXICOGÉNESIS Y VARIACIÓN LINGÜÍSTICA

GUERRERO RUIZ, P., B. PASTOR PASTOR y L. DEPESTRE CATONY. “Glosario popular cubano (estudio de cubanismos actuales)", en: Lenguaje y Textos, 2002, 20, pp. 139-160.

HAENSCH, G. y R. WERNER (dir.) Diccionario del español de Cuba. Madrid: Gredos, 2000.

HENRÍQUEZ UREÑA, P. Observaciones sobre el español en América y otros estudios filológicos. Buenos Aires: Academia Argentina de Letras, 1976.

HOPE, T. E. Lexical Borrowing in the Romance Languages: a Critical Study of Italianisms in French and Gallicisms in Italian from 1100 to 1900. Oxford: Basil Blackwell, 1971.

LIPSKI, J. M. "El español de América en contacto con otras lenguas", en LACORTE, M. (coord.): Lingüística aplicada del español. Madrid: Arco/ Libros, 2007, 309-345.

LÓPEZ GARCÍA, Á. "El contacto de lenguas y la singularidad americana", en: Calvo Pérez, J. (ed.): Teoría y práctica del contacto: el español de América en el candelero. Madrid/ Frankfurt: Iberoamericana/ Vervuert, 2001, 7-30.

LÓPEZ MORALES, H. "Fray Bartolomé de Las Casas y la extinción de las lenguas indígenas antillanas. El caso de Cuba", en: Anuario de Lingüística Hispánica, 1996-97, 12, 361-368.

LÓPEZ MORALES, H. El español del Caribe. Madrid: Mapfre, 1992.

LÓPEZ MORALES, H. Estudios sobre el español de Cuba. New York: Las Américas, 1971.

MARTINELL GIFRE, E. La comunicación entre españoles e indios: palabras y gestos. Madrid: Mapfre, 1992.

MARTÍNEZ-SHAW, C. "La procedencia geográfica de la emigración española a América (1492-1824)", en: Españoles de ambas orillas. Madrid: Ebcomp, 1998 25-40.

MENÉNDEZ, A. "Léxico de Cuba: panorama geolectal", en: Aleza, M. y SanMartín, J. (eds.): Estudios de lexicografía y léxico cubanos. Universitat de València, 2004, pp. 101-117.

ORTIZ, F. "Los afronegrismos de nuestro lenguaje", en: Revista bimestre cubana, 1922, 17/ 6, 321-336.

ORTIZ, F. Contrapunteo cubano del tabaco y el azúcar. Caracas: Biblioteca Ayacucho, [1940] 1978.

ORTIZ, F. Nuevo catauro de cubanismos. La Habana: Ciencias Sociales, 1985.

ORTIZ LÓPEZ, L. A. "La variante hispánica haitianizada en Cuba: otro rostro del contacto lingüístico en el Caribe", en: FORASTIERI BRASCHI, E. et al. (eds.): Estudios de lingüística hispánica, Homenaje a $M^{a}$ Vaquero. Universidad de Puerto Rico, 1999, 428-456. 
PAZ PÉREZ, C. De lo popular y lo vulgar en el habla cubana. La Habana: Editorial de Ciencias Sociales, 1988.

PERL, M. "La influencia del francés y del francés criollo en el español del Caribe", Islas, 1981, 68, pp. 163-176.

PICHARDO MOYA, F. Los aborígenes de Las Antillas. México: Fondo de Cultura Económica, 1956.

PICHARDO Y TAPIA, E. Diccionario provincial casi razonado de vozes y frases cubanas. La Habana: Ciencias Sociales, [1836] $1976^{5}$.

SÁNCHEZ-BOUDY, J. Diccionario mayor de cubanismos. Miami: Universal, 1999.

SANTIESTEBAN, A. El habla popular cubana de hoy. Una tonga de cubichismos que le oí a mi pueblo. La Habana: Ciencias Sociales, 1985.

UEDA, H. y RUIZ TINOCO, A. "Varilex. Variación léxica del español en el mundo. Proyecto internacional de investigación léxica", en: Ávila, R. et al.: Pautas y pistas en el análisis del léxico hispano(americano). Madrid/Frankfurt: Iberoamericana/Vervuert, 2003, 141-278.

VALDÉS BERNAL, S. "Las lenguas africanas y el español coloquial de Cuba", Santiago, 1978, 31, 81-107.

VALDÉS BERNAL, S. "Las lenguas indoamericanas y el español hablado en Cuba", América Indígena, [1981] 1988, 48/ 2, 403-417.

VALDÉS BERNAL, S. "En torno a los remanentes del aruaco insular en el español de Cuba", Islas, 1984, 77 (enero-abril), 5-22.

VALDÉS BERNAL, S. La evolución de los indoamericanismos en el español hablado en Cuba. La Habana: Ciencias Sociales, 1986.

VALDÉS BERNAL, S. "Los gitanismos del español en Cuba", Anuario L/ L, 1990, 21, 192-223 [publicado ulteriormente como capítulo de libro en Inmigración y lengua nacional. La Habana: Academia, 1994, 81-108].

VALDÉS BERNAL, S. Las lenguas indígenas de América y el español de Cuba, 2 vols., La Habana: Academia, 1991-1993.

VALDÉS BERNAL, S. "En torno a las lenguas aborígenes de Cuba del periodo colonial", Langues et Linguistique, 1994a, 20, 153-172.

VALDÉS BERNAL, S. "La inmigración peninsular y canaria en Cuba desde el punto de vista lingüístico", en: Inmigración y lengua nacional. La Habana: Academia, 1994b, 50-80.

VALDÉS BERNAL, S. "El legado carabalí en el español de Cuba”, Anuario de Lingüística Hispánica, 1996-97, 12, 449-456.

VALDÉS BERNAL, S. Lengua nacional e identidad cultural del cubano, La Habana: Editorial de Ciencias Sociales, 1998.

VALDÉS BERNAL, S. "Panorámica histórica de las lenguas en contacto en Cuba", en: ALEZA, M. et al. (eds.): El contacto lingüístico en el desarrollo de las lenguas occidentales. Quaderns de Filologia. Estudis Lingüístics, 1999, 4, 223-238. 
VALDÉS BERNAL, S. "Cuba: ejemplo histórico de lenguas en contacto", en: KERSTIN S. y J. KLARE (comps.), Romanische Sprachen in Amerika. Fetschirft für Hans-Dieter Paufler zum 65, Gegurstag, Frankfurt an Main, Peter Lang, Europäischer Verlag der Wissenschaften, 2002, 301-311.

VALDÉS BERNAL, S. "Las bases lingüísticas del español en Cuba”, en: Domínguez Hernández, M. A. (ed.): La lengua en Cuba. Estudios. Biblioteca de la Cátedra de Cultura cubana Alejo Carpentier, Universidad de Santiago de Compostela, 2007, 27-55.

VARELA MERINO, E. Los galicismos en el español de los siglos XVI y XVII, Anejos de la Revista de Filología Española, 2 vols., Madrid: CSIC, 2009.

\section{Anexo: Casos de lexicalización}

Aceitar. Sobornar.

Aceitoso, sa. coloq. desp. Persona servil.

Aguaitacaimán. Ave zancuda.

Aguajirado. coloq. Persona tímida.

Butacón. Butaca.

Desmameyar. coloq. Desbaratar.

Guaricandilla, coloq. desp. Persona de aspecto vulgar.

Guayabera. Camisa criolla.

Guayabero. coloq. Mentiroso, cuentista.

Guayabita (del Pinar). Licor.

Guayabito. 1. Ratoncito. 2. coloq. desp. Cobarde.

Guayabudo. coloq. desp. Persona mulata.

Hamaquero. Persona falsa.

Jinetera, Meretriz de turistas.

Malanguita. 1. Planta ornamental. 2. Corte de pelo masculino.

Papalotero. coloq. Mentiroso.

Pejenigua. Muchacho pequeño y vivaracho. 